\title{
The Physico-Chemical Characteristics and Effect of Albumin Concentration and Whipping Time on Foam Density of Tomato Pulp
}

\author{
B. Gowtham Singh ${ }^{1}$, K. Ravindra ${ }^{1 *}$, Y. Srinivas ${ }^{1}$, M. Ambedkar ${ }^{1}$ and Rohitash Kumar ${ }^{2}$ \\ ${ }^{1}$ College of Agricultural Engineering, Acharya N. G. Agricultural Engineering, Guntur \\ (Andhra Pradesh) - 522101, India \\ ${ }^{2}$ College of Agricultural Engineering and Technology, Shere-e-Kashmir University of Science \\ and Technology of Kashmir, Srinagar (Jammu and Kashmir)-190025, India \\ *Corresponding author
}

\begin{abstract}
A B S T R A C T
Tomato is one of the most important protective food crops in India. It is grown in 865,000 ha area with total production of 18.2 MT (Anonymous, 2013). So the present study is undertaken to study the physico-chemical characteristics and Effect of albumin concentration and whipping time on foam density of tomato pulp. Physico-chemical analysis of the pulp was carried out in the laboratory. Evaluation of $\mathrm{pH}$, acidity, moisture content, TSS, foam density and stability was done. The foam density decreased to approximately 0.682 and $0.33 \mathrm{~g} / \mathrm{cc}$ after $4 \mathrm{~min}$ of whipping when egg albumin concentration was $1.5 \%$ and $4.5 \%$ respectively. Foam density decreased with increased whipping time. After the initial decrease, however, as light increase in the foam density was observed after 7 min of whipping. Tomato pulp of optimum foam density was formed after $4.5 \mathrm{~min}$ of whipping. The moisture content, $\mathrm{pH}$, acidity and TSS of untreated tomato pulp were $95.30 \%$ w.b., 3.902, 0.29 and $5^{\circ}$ brix respectively. Similarly, the values for foam dried tomato pulp were $94.35 \%$ w.b., $3.945,0.23$ and $5^{\circ}$ brix respectively. Similarly, the values for foam dried tomato pulp were $94.35 \%$ w.b., $3.945,0.23$ and $5^{\circ}$ brix respectively. Drying temperatures within the experimental range of $60^{\circ} \mathrm{C}-80^{\circ} \mathrm{C}$ did not significantly affect the textural properties and shrinkage of foams.
\end{abstract}

Keywords

Tomato

(Lycopersicum

esculentum Mill),

Solanaceae, Vegetable

Article Info

Accepted:

24 September 2018

Available Online:

10 October 2018

\section{Introduction}

Tomato (Lycopersicum esculentum Mill) is one of the world's most commercially produced vegetable, belongs to the family of Solanaceae. Tomato is one of the most important protective food crops in India. It is grown in 865,000 ha area with total production of 18.2 MT (Anonymous, 2013). The major tomato producing states are Bihar, Karnataka, Uttar Pradesh, Orissa, Andhra
Pradesh, Maharashtra, Madhya Pradesh and west Bengal.

Tomato is consumed throughout the year indifferent forms. It is very appetizing, refreshing and has a pleasing taste. Fruits are eaten as raw or cooked. It can be cooked alone or mixed with other vegetables. Even though the ripe tomato contains about $94 \%$ moisture, it is an excellent source of minerals and vitamins. Tomato contains large amounts of 
vitamin $\mathrm{C}$, and $\mathrm{A}$, providing $40 \%$ and $15 \%$ of the daily value, respectively.

However, marketing of fresh tomato during the season is a great problem because of its short postharvest life, which leads to high postharvest losses. The postharvest losses reported for tomatoes are around 50\% (Olayemi et al., 2010).

Drying is a process of moisture removal due to simultaneous heat and mass transfer from the surrounding environment. Rate of moisture transfer is governed by some of factors such as physical nature of the food, temperature, composition and initial moisture content.

The foam mat drying is an effective method of dehydrating liquid foods in short times. Due to the porous structure of the foamed materials, mass transfer is enhanced leading to shorter dehydration times. It is the simplest method of drying in which a liquid food concentrate along with a suitable foaming agent is whipped to form a stable foam and is subjected to dehydration in the form of a mat of foam. The capillary via foam pores facilitates moisture loss which makes the foam mat drying approximately three times faster than the drying of a similar layer of liquid.

Rate of drying in this process is comparatively very high because of enormous increase in liquid-gas interface, in spite of the fact that the heat transfer is impeded by a large volume of gas present in the foamed mass.

This technique can be successfully employed for drying a variety of fruit juice concentration and pulps. The dried powders have good reconstitution characteristics. These studies are particularly applicable for drying of fruit and vegetable pulps drying such as guava, banana and tomato etc., with some of the commonly used foaming agents like egg albumin and soya protein.
In view of the above points, the present study is undertaken to study the physico-chemical characteristics and Effect of albumin concentration and whipping time on foam density of tomato pulp.

\section{Materials and Methods}

\section{Physico-chemical analysis of pulp}

Physico-chemical analysis of the pulp was carried out in the laboratory. Evaluation of $\mathrm{pH}$, acidity, moisture content, TSS, foam density and stability was done.

\section{Potential of hydrogen (pH)}

$\mathrm{pH}$ was measured using $\mathrm{pH}$ meter (Plate 1). Special probes were used to measure the $\mathrm{pH}$ of semi-solid substances. A typical $\mathrm{pH}$ meter consists of a special measuring probe (a glass electrode) connected to an electronic meter that measured and displayed the $\mathrm{pH}$ reading.

Firstly, $\mathrm{pH}$ meter was calibrated by dipping the glass electrode into buffers (test solutions of known $\mathrm{pH}$ ). Then, the glass electrode was dipped in the substance of unknown $\mathrm{pH}$. Then, the $\mathrm{pH}$ of the substance was measured. Finally, bulb was cleaned carefully with absorbent tissue paper.

\section{Acidity}

Titration is a chemical process used in ascertaining the amount of constituent substance i.e., an acid or an alkali in a sample. The materials required for this method using a colored indicator are given below.

A laboratory burette ( 25 or $50 \mathrm{ml}$ )

A pipette $(10 \mathrm{ml})$

Beaker (250ml)

A filter (muslin cloth or fine filter)

An extractor or homogenizer

A bottle of distilled water 
Sodium Hydroxide $(\mathrm{NaOH})$

Phenolphthalein

The procedure for the measurement of acidity was given below.

$5 \mathrm{ml}$ of the sample solution in two triplicates was pipetted out into a beaker of $250 \mathrm{ml}$ capacity.

3 drops of phenolphthalein was added in to the sample solution in beaker.

The tap on the burette was shut and using a funnel the $0.1 \mathrm{~N}$ solution of $\mathrm{NaOH}$ was poured into the burette until it reached the zero mark.

Slowly, the $\mathrm{NaOH}$ was titrated into the sample solution (with a $25 \mathrm{ml}$ burette or an automatic burette).

Care was taken in avoiding to adhere to the glass that the $\mathrm{NaOH}$ was dropped directly into the solution and to continually swirl the solution in the beaker to keep it thoroughly mixed.

At the end point neutrality, the phenolphthalein indicator changed very rapidly from colorless to pink.

The average of the readings was noted.

\section{Moisture content}

Moisture content of tomato pulp was determined by oven drying method. A20 g of samples was weighed in triplicate and dried for about 1 hrin electric oven at $130^{\circ} \mathrm{C}$ (Plate 2) (AOAC, 2000).

The observations were recorded and moisture content was computed by using following formula.

Moisture content $(\%)=\frac{\frac{x}{y}}{y}{ }_{100(1)}$
Where

$X=$ Weight of the dish + Sample before drying $(\mathrm{g})$

$\mathrm{Y}=$ Weight of the dish + Sample after drying (g)

\section{Total Soluble Solids (TSS)}

Degree Brix $\left({ }^{\circ}\right.$ Brix $)$ is the sugar content of an aqueous solution. $1^{\circ}$ Brix is $1 \mathrm{~g}$ of sucrose in $100 \mathrm{~g}$ of solution and represents the strength of the solution as percentage by weight $(\% w)$ (strictly spacing, by mass) (AOAC, 2006). If the solution contains dissolved solids other than pure sucrose, then degree Brix is only approximate the dissolved solid content. The degree Brix is traditionally used in the wine, sugar, fruit juice, and honey industries.

The refractometer (Plate 3 and 4) was held horizontally and pointed towards a light source. By looking into the eye piece the scale was rotated focusing knob until the image of the scaled was clear.

Temperature is important in the measurement of refractive indices, therefore the calibrating drops of water must be at the same temperature as the sample to measure. Refractometer was calibrated by placingseveral drops of distilled water of the proper temperature between the cover and the prism. While observing through the eyepiece, the scale was rotated calibrating screw so the boundary line which separates the light and dark areas of the image is aligned with the zero line on the scale.

The cover was lifted and the calibrating water was dried off from the prism. One to two drops of the sample was placed on the prism and the cover was closed.

With cover and prism facing a light source, by looking into the eyepiece and the boundary 
line was noted. The correct measurement in percentage of sugar is read at the point where the boundary line crossed the scale.

When finished, cover and prism were carefully cleaned and dried.

For measurement of sugar content in samples, $50 \mathrm{mg}$ of sample was taken and homogenized with the distilled water of $200 \mathrm{ml}$. The supernatant was transferred into separate beaker. The refractometer was calibrated for drops of distilled water of the proper temperature between the cover and the prism. While observing through the eyepiece, the scale calibrating screw was rotated so the boundary line which separates the light and dark areas of the image was aligned with the zero line on the scale.

After setting the zero scale, one to two drops of the sample to be tested was placed on the prism and the cover was closed. With cover and prism facing a light source, looking into the eyepiece noted where the boundary line appeared. When finished, carefully cleaned and dried the cover and prism.

\section{Foam density}

The density was determined by filling a $50 \mathrm{ml}$ graduated cylinder with tomato foam and height of foam was measured using a scale and then weighed. By measuring the volume of the cylinder, foam density was calculated and expressed in $\mathrm{g} / \mathrm{cc}$.

Foam density $=\frac{\text { Foam Weight }(\mathrm{CBJ})}{\text { Foam Volume }(\mathrm{cos})}(2)$

\section{Foam stability}

The stability was determined by measuring the volume of the foam in a $50 \mathrm{ml}$ graduated cylinder that was initially full after being heated in an oven at $70^{\circ} \mathrm{C}$ for $60 \mathrm{~min}$. The obtained stability was expressed in percentage.

\section{Foam mat drying of tomato pulp}

The drying of the tomato foam was conducted in a tray drier (Plate 5) with forced air circulation. The foam was deposited evenly in aluminum trays (rectangular trays measuring $78 \mathrm{~cm}$ in length and $38 \mathrm{~cm}$ width) by filling the trays with $5 \mathrm{~mm}$ high foam mass to occupy the entire surface of the drying tray. The foam drying processes of the control (tomato pulp without albumin addition) and treatment with albumin addition were compared at two drying temperatures $\left(60^{\circ} \mathrm{Cand} 80^{\circ} \mathrm{C}\right)$. To obtain the drying curves, each tray with foam was weighed at 30min intervals for initial $3 \mathrm{~h}$ and every $1 \mathrm{~h}$ after that a constant weight was reached with a mass variation of less than $0.2 \%(\mathrm{~m} / \mathrm{m})$, i.e., when the moisture equilibrium was reached at the temperature of the drying air.

\section{Results and Discussion}

\section{Optimum parameters for preparation of tomato pulp}

Physically mature, firm texture fruits were found suitable for preparation of tomato pulp. For boiling of $1 \mathrm{~kg}$ of tomatoes, 1litre of water was found adequate. A boiling temperature range of $80^{\circ} \mathrm{C}$ and boiling period of $4-5$ minutes were found to be optimal for the loosening of the peel.

\section{Preparation of tomato pulp}

The average yield of tomato pulp was $42 \%$ and the remaining $58 \%$ has gone waste in the form of seeds and peel (Plate. 6).

\section{Physico-chemical properties of tomato pulp}

The different physico-chemical properties of tomato pulp were determined in the laboratory. The results were given in the following Table 1. 
Plate.1 pH meter

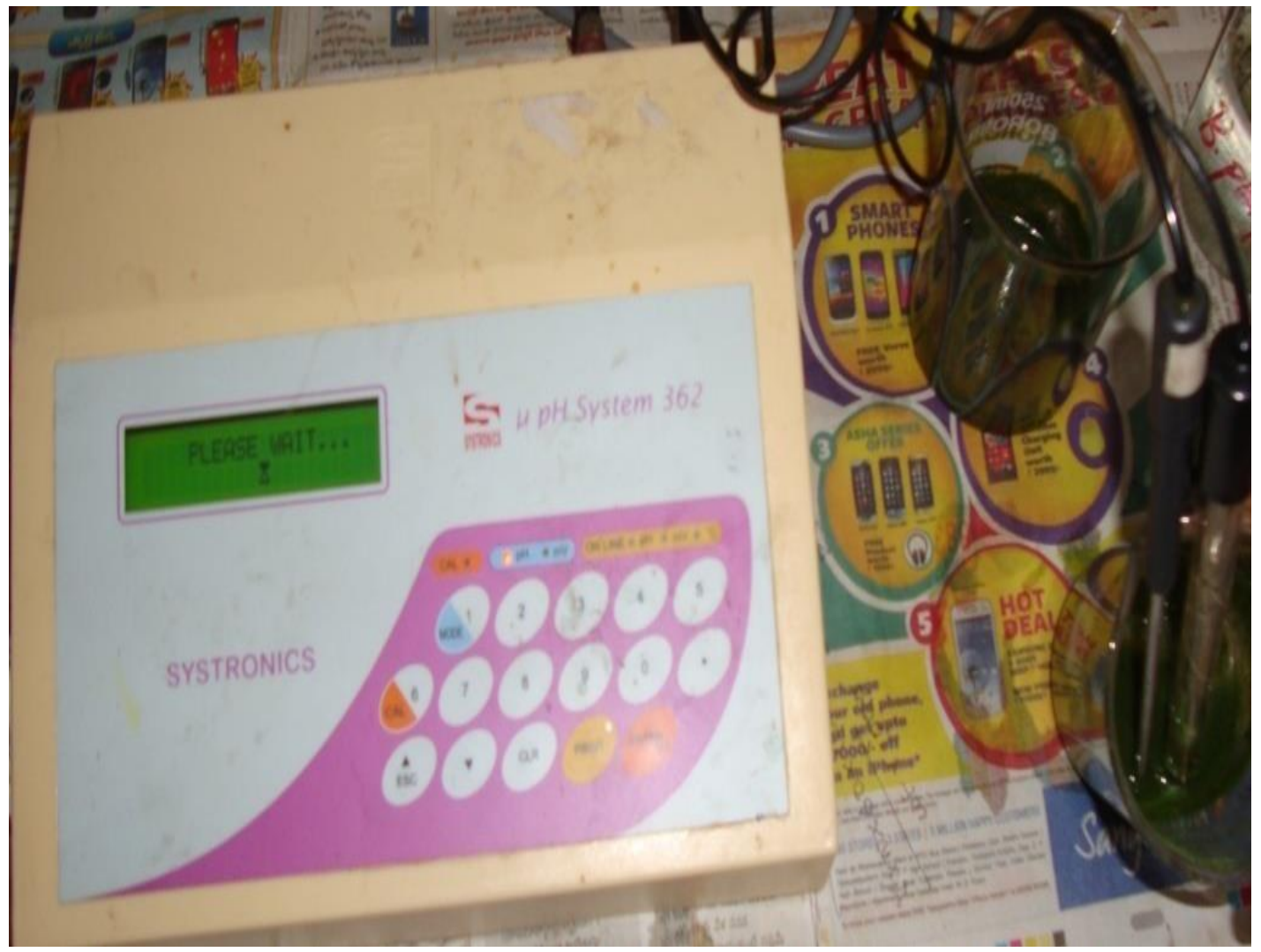

Plate.2 Hot air oven

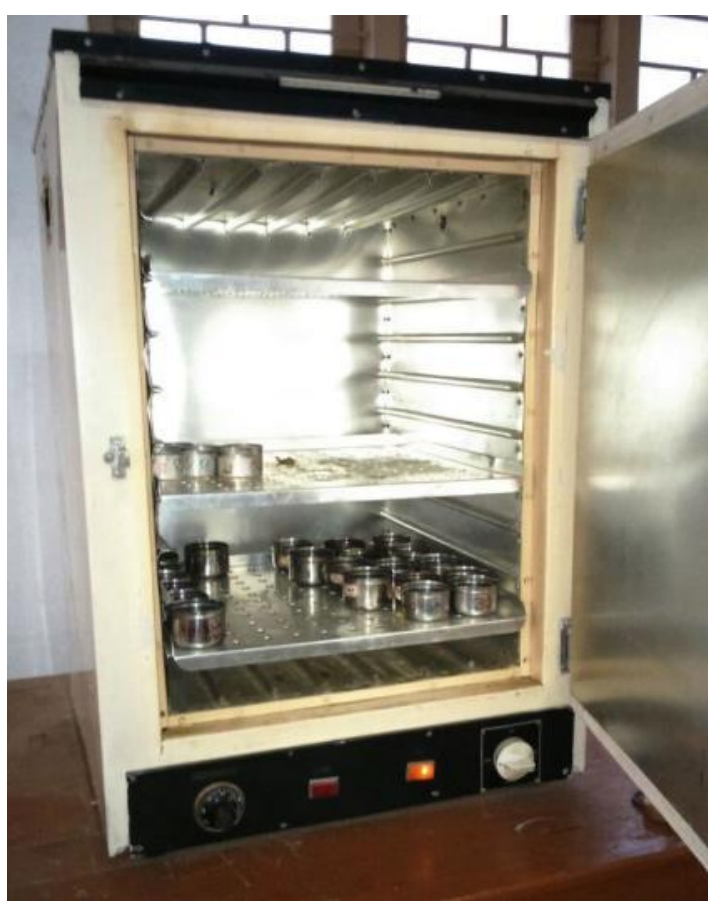


Plate.3 Brix scale

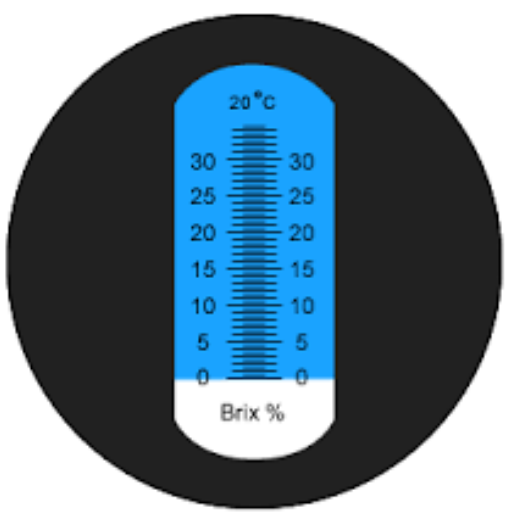

Plate.4 Refractometer

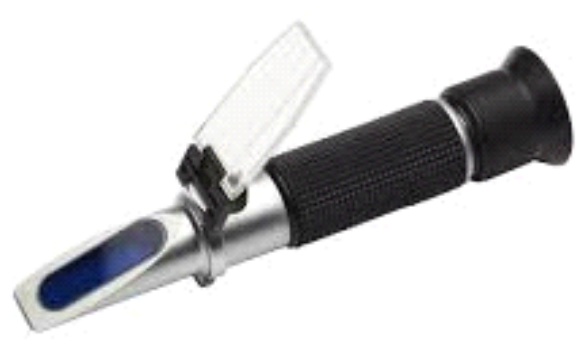

Plate.5 Tray drier

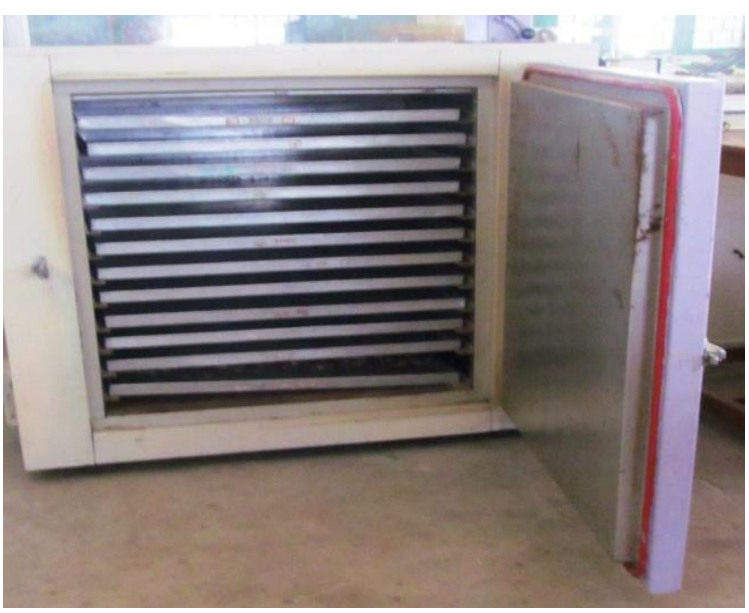

Plate.6 Tomato pulp without and with addition of egg albumin

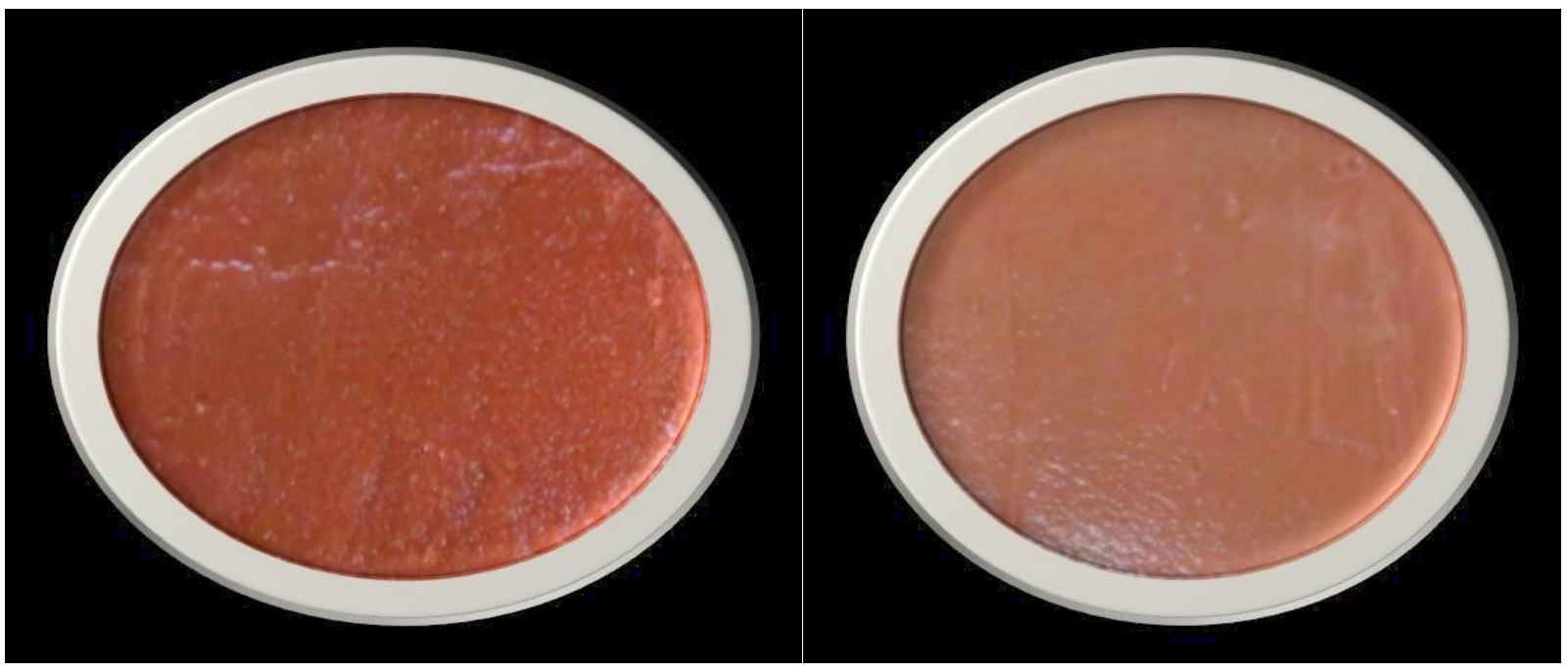


Fig.1 Effect of albumin concentration on foam density of tomato pulp.

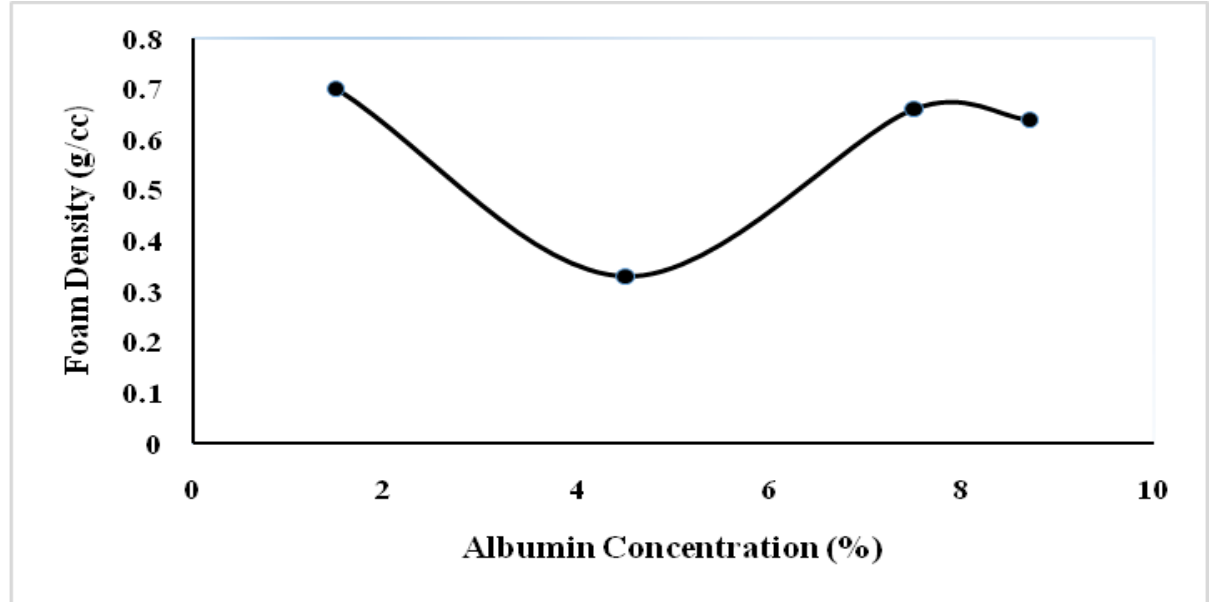

Fig.2 Effect of whipping time on foam density of tomato pulp

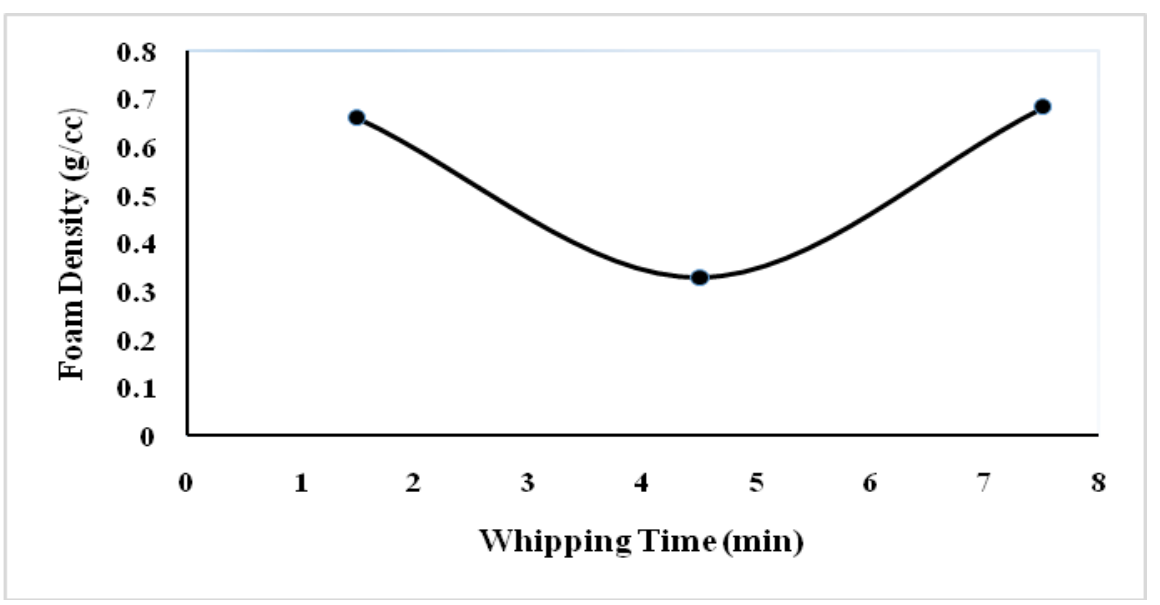

Table.1 Physico-chemical properties of tomato pulp

\begin{tabular}{|c|l|l|l|}
\hline S. No & Parameter & Control & Treatment \\
\hline 1 & pH & 3.90 & 3.94 \\
\hline 2 & Acidity & 0.29 & 0.23 \\
\hline 3 & Moisture $(\%$ w.b) & 95.30 & 94.35 \\
\hline 4 & Total soluble solids $\left({ }^{\circ}\right.$ Brix $)$ & 5 & 5 \\
\hline
\end{tabular}

Table.2 Effect of albumin concentration on foam density of tomato pulp

\begin{tabular}{|l|r|r|}
\hline S. No & Albumin concentration $(\%)$ & Foam density(g/cc) \\
\hline 1 & 1.5 & 0.70 \\
\hline 2 & 4.5 & 0.33 \\
\hline 3 & 7.5 & 0.66 \\
\hline 4 & 8.7 & 0.64 \\
\hline
\end{tabular}


Table.3 Effect of whipping time on foam density of tomato pulp

\begin{tabular}{|r|r|c|}
\hline S. No & Whipping time(min) & Foam density(g/cc) \\
\hline 1 & 1.5 & 0.66 \\
\hline 2 & 4.5 & 0.33 \\
\hline 3 & 7.5 & 0.682 \\
\hline
\end{tabular}

\section{Effect of albumin concentration on foam density of tomato pulp}

The effect of concentration of the egg albumin on the foam density was analyzed by adding different concentrations of the foaming agent to the tomato pulp and then whipping the tomato pulp. As the concentration of the egg albumin increased, the foam density decreased (Table 2). The foam density decreased to approximately 0.682 and $0.33 \mathrm{~g} / \mathrm{cc}$ after $4 \mathrm{~min}$ of whipping when egg albumin concentration was $1.5 \%$ and $4.5 \%$ respectively. Excessive egg albumin concentration beyond a certain value did not further reduce the foam density (Fig. 1).

\section{Effect of whipping time on foam density of tomato pulp}

The effect of whipping time on the foam density was analyzed by whipping the tomato pulp for different time periods (Fig.2). As seen from the graph, foam density decreased with increased whipping time. After the initial decrease, however, as light increase in the foam density was observed after $7 \mathrm{~min}$ of whipping (Table 3). The air was brought into the tomato pulp and entrapped in the liquid as bubbles.

This led to a decrease of foam density as whipping time increased. Tomato pulp of optimum foam density was formed after $4.5 \mathrm{~min}$ of whipping. Beyond this time the foam density increased. The increase in foam density was attributed to more liquid film thinning and more bubble was rupture during extended whipping.
The tomatoes are one of the most commonly available vegetables and they are good sources of vitamins $\mathrm{A}$ and $\mathrm{C}$. The tomato powder is used in making tomato sauce, tomato soup and used in other food making processes. Freshly available tomatoes were acquired, properly washed, boiled, sliced, seed was removed and pulp was prepared, the pulp was mixed up with $4.5 \%$ albumin concentration and whipped for 4.5 minutes.

The extracted pulp was subjected to foam mat drying at temperatures of $60^{\circ} \mathrm{C}$ and $80^{\circ} \mathrm{C}$.

The following conclusions were drawn from this study.

The yield of tomato pulp was $42 \%$.

Whipping time and egg albumin concentration affected the tomato foam density.

The moisture content, $\mathrm{pH}$, acidity and TSS of untreated tomato pulp were $95.30 \%$ w.b., $3.902,0.29$ and $5^{\circ}$ brix respectively. Similarly, the values for ${ }^{\circ}$ brix respectively.

Similarly, the values for foam dried tomato pulp were $94.35 \%$ w.b., $3.945,0.23$ and $5^{\circ}$ brix respectively. Slight variation was observed among the physico-chemical properties of treated and untreated tomato pulp.

Drying temperatures within the experimental range of $60^{\circ} \mathrm{C}-80^{\circ} \mathrm{C}$ did not significantly affect the textural properties and shrinkage of foams. 


\section{References}

Anonymous. 2013. Vegetable production map based on the crop wise production pattern. Indian Horticulture Database, NHB, MoA, GoI, India.

AOAC. 2000. Official Methods of Analysis, 16th edn. Association of Official Analytical Chemist, Washington.
AOAC. 2006. Official Methods of Analysis 970.59. Solids (Soluble) in Tomato Products. Association of Official Analytical Chemist, Washington.

Olayemi FF., Adegbola JA., Bamishaiye EI and Daura AM. 2010. Assessment of post-harvest challenges of small scale farm holders of tomato. Bayero. Journal of Puree and Applied Science, 3(2), 3042.

\section{How to cite this article:}

Gowtham Singh, B., K. Ravindra, Y. Srinivas, M. Ambedkar and Rohitash Kumar. 2018. The Physico-Chemical Characteristics and Effect of Albumin Concentration and Whipping Time on Foam Density of Tomato Pulp. Int.J.Curr.Microbiol.App.Sci. 7(10): 3053-3061. doi: https://doi.org/10.20546/ijcmas.2018.710.356 